\title{
Assessment of 105 Patients with Angiotensin Converting Enzyme-Inhibitor Induced Angioedema
}

\author{
Eva Rye Rasmussen, ${ }^{1}$ Christian von Buchwald, ${ }^{1}$ Mia Wadelius, ${ }^{2}$ \\ Sumangali Chandra Prasad, ${ }^{3}$ Shailajah Kamaleswaran, ${ }^{3}$ Kawa Khaled Ajgeiy, ${ }^{3}$ \\ Georg Authried, ${ }^{3}$ Kristine Appel U. Pallesen, ${ }^{3}$ and Anette Bygum ${ }^{3}$ \\ ${ }^{1}$ Department of Otorhinolaryngology, Head \& Neck Surgery and Audiology, Rigshospitalet, \\ University of Copenhagen, København, Denmark \\ ${ }^{2}$ Department of Medical Sciences, Clinical Pharmacology and Science for Life Laboratory, Uppsala University, Uppsala, Sweden \\ ${ }^{3}$ Department of Dermatology and Allergy Centre, Odense University Hospital, Odense, Denmark \\ Correspondence should be addressed to Eva Rye Rasmussen; eva.rye.rasmussen@dadlnet.dk
}

Received 9 October 2016; Revised 19 December 2016; Accepted 18 January 2017; Published 14 February 2017

Academic Editor: David W. Eisele

Copyright (C) 2017 Eva Rye Rasmussen et al. This is an open access article distributed under the Creative Commons Attribution License, which permits unrestricted use, distribution, and reproduction in any medium, provided the original work is properly cited.

Objective. To asses a cohort of 105 consecutive patients with angiotensin converting enzyme-inhibitor induced angioedema with regard to demographics, risk factors, family history of angioedema, hospitalization, airway management, outcome, and use of diagnostic codes used for the condition. Study Design. Cohort study. Methods. This was a retrospective cohort study of 105 patients with angiotensin converting enzyme-inhibitor induced angioedema in the period 1995-2014. Results. The cohort consisted of 67 females and 38 males (F:M ratio 1.8), with a mean age of 63 [range 26-86] years. Female gender was associated with a significantly higher risk of angiotensin converting enzyme-inhibitor induced angioedema. $6.7 \%$ had a positive family history of angioedema. Diabetes seemed to be a protective factor with regard to angioedema. 95\% experienced angioedema of the head and neck. $4.7 \%$ needed intubation or tracheostomy. 74 admissions took place during the study period with a total of 143 days spent in the hospital. The diagnosis codes most often used for this condition were "DT783 Quincke's oedema" and "DT78.4 Allergy unspecified". Complement $\mathrm{Cl}$ inhibitor was normal in all tested patients. Conclusion. Female gender predisposes to angiotensin converting enzyme-inhibitor induced angioedema, whereas diabetes seems to be a protective factor.

\section{Introduction}

Angioedema is a transient nonpitting swelling of the dermis and subcutis or submucosa which occurs in a variety of diseases. Asphyxiation is a risk when angioedema localizes in the oral cavity, pharynx, or larynx [1]. When the physician encounters patients with severe acute and/or recurrent angioedema, both treatment and assessment might be a challenge [2]. Angioedema can occur as an adverse effect to several medications, but one drug class is overrepresented, namely, angiotensin converting enzyme-inhibitors (ACEi) $[1,3]$. Over the past twenty years, it has become evident that ACEi induced angioedema is frequently misdiagnosed as allergic reactions resulting in the use of noneffective antiallergic medications and failure to withdraw the offending drug
$[2,4]$. In a few cases, a genetic predisposition to ACEi induced angioedema has been found [5-7]. Seemingly, ACEi induced angioedema is related to polygenetic and demographic as well as environmental factors such as age, race, gender, comorbidity, and smoking, but most available studies are describing heterogeneous and relatively small sample sizes $[1,8]$. Also standardized clinical assessments of patients regarding other causes of angioedema are often lacking.

This retrospective study of the clinical characteristics of patients suffering from ACEi induced angioedema was carried out at a Danish Department of Dermatology and Allergy Centre. Patients referred to the department had a history of severe and/or recurrent angioedema of unknown cause and were thoroughly assessed using a systematic angioedema guideline. The main objectives of the study were 
to describe a large presumed Caucasian cohort with ACEi induced angioedema. Furthermore, previously identified risk factors would be assessed to see whether we could validate the findings. Also, the study served as a quality study for our department, which holds the regional service for angioedema assessment.

\section{Materials and Methods}

A retrospective study of patients diagnosed with ACEi induced angioedema in the period 1995-2014 was performed at a single department of dermatology and allergology, Odense University Hospital, which serves a population of 1.2 million people. Patient data was entered into a database in order to ensure correct and reliable data collection. Stata ${ }^{\circledR}$ version 14 (StataCorp. 2015, Stata Statistical Software: Release 14. College Station, TX: StataCorp LP.) was used as database system and for analysis. For statistical analysis, differences of proportion test together with multivariate logistic regression analyses were used. $p$ values $\leq 0.05$ were considered statistically significant. Relative risk calculation was based on the study population and data (ACEi treated males and females) from the Danish registry on sale of pharmaceuticals 1996-2014 [9]. As there was no control group, statistics was performed comparing groups of patients with each other (i.e., males and females, smokers and nonsmokers, and patients with and without hypertension).

2.1. Ethics. This study was approved by the Danish Data Protection Agency (jr. number 14/35206) and the Danish National Board of Health (jr. number 3-3013-805/1/) as appropriate.

\section{Results}

Of 734 consecutive patients assessed due to angioedema, 105 patients were found to have ACEi induced angioedema and were included in the study (Table 1). There was a predominance of females and the mean age was 63 years [range 26-86 years]. The age distribution is shown in Figure 1. The female overrepresentation reached statistical significance ( $p=0.006$; 95\% confidence interval (CI) 0.09-0.47). Using MedStat.dk, which is a tool to extract data on prescribed pharmaceuticals in Denmark, we found that $23 \%$ more males than females receive an ACEi in the study period [9]. The relative risk of angioedema due to ACEi in females versus males was found to be 1.4 [9].

Patients were most often referred by their general practitioner; $9.5 \%$ of them were referred twice due to recurrent angioedema episodes after withdrawal of ACEi. Most patients had experienced more than one angioedema episode prior to referral (Table 1). Relatively few patients needed airway management (Table 2).

More than half the patients had been admitted to hospital due to angioedema at least once with a total of 74 admissions and 143 patient-days spent in hospital (Table 3). Furthermore, 48 of 100 patients had been assessed at an Emergency Department due to angioedema, while the history of Emergency Department visits was unknown for five patients (Table 3).

A variety of diagnostic codes (International Classification of Diseases version 10) were used when admitting
TABLE 1: Basic data.

\begin{tabular}{|c|c|}
\hline Parameter & \\
\hline Patients, $n$ & 105 \\
\hline Male : female & $38: 67$ \\
\hline Caucasians & $104(99 \%)$ \\
\hline Age, mean, years & $\begin{array}{l}63 \text { [range 26-86] } \\
\quad(\mathrm{SD} 12.42)\end{array}$ \\
\hline $\begin{array}{l}\text { Referred }>1 \text { due to recurrent } \\
\text { angioedema, } n(\%)\end{array}$ & $10(9.5 \%)$ \\
\hline \multicolumn{2}{|l|}{ Referring medical specialty } \\
\hline (i) General practitioner & 47 \\
\hline (ii) Internal medicine & 28 \\
\hline (iii) Emergency department & 11 \\
\hline (iv) Otorhinolaryngology & 10 \\
\hline (v) Referred from 2 specialties & 6 \\
\hline (vi) Dermatology & 1 \\
\hline (vii) Allergy centre & 1 \\
\hline (viii) Unknown & 1 \\
\hline $\begin{array}{l}\text { Follow-up, patient-months } \\
\text { (mean) }\end{array}$ & $700(6.7)$ \\
\hline \multicolumn{2}{|l|}{ History of drug rash } \\
\hline No & $72.3 \%$ \\
\hline Yes & $27.6 \%$ \\
\hline \multicolumn{2}{|l|}{ History of allergic disease } \\
\hline No & $76.1 \%$ \\
\hline Yes & $22.0 \%$ \\
\hline Unknown & $1.9 \%$ \\
\hline \multicolumn{2}{|l|}{ Smoking } \\
\hline No & $38.0 \%$ \\
\hline Yes & $24.8 \%$ \\
\hline Unknown & $37.1 \%$ \\
\hline \multicolumn{2}{|l|}{ Family history of angioedema } \\
\hline No & $75.2 \%$ \\
\hline Yes & $6.7 \%$ \\
\hline Unknown & $18.0 \%$ \\
\hline \multicolumn{2}{|l|}{$\begin{array}{l}\text { Number of angioedema episodes } \\
\text { prior to referral }\end{array}$} \\
\hline 1 & $20.0 \%$ \\
\hline 2 & $7.6 \%$ \\
\hline $3-5$ & $17.1 \%$ \\
\hline $6-10$ & $9.5 \%$ \\
\hline $11-20$ & $4.8 \%$ \\
\hline $21-50$ & $1.9 \%$ \\
\hline$>50$ & $8.6 \%$ \\
\hline Unknown & $30.5 \%$ \\
\hline
\end{tabular}

angioedema patients with "DT 78.3 Quincke's oedema" and "DT 78.4 Allergy without specification" used in $75-90 \%$ of cases in both the Emergency Department and other inpatient departments (Table 3). 
TABLE 2: Descriptive angioedema incident data. Some patients had experienced angioedema in more than one location; thus, the numbers does not add up to 100 .

\begin{tabular}{|c|c|c|}
\hline Parameter & & \\
\hline \multicolumn{3}{|c|}{ Localization of angioedema, $n,(\%)$} \\
\hline (i) Head and neck & & $100(95.2 \%)$ \\
\hline (ii) Peripheral & & $14(13.3 \%)$ \\
\hline (iii) Abdominal & & $3(2.9 \%)$ \\
\hline Concomitant rash, $n,(\%)$ & & $19(18 \%)$ \\
\hline \multicolumn{3}{|c|}{ Treatment of acute attacks, $n,(\%)$} \\
\hline Antihistamines & $96(91.4 \%)$ & Efficacy reported by $62.5 \%$ \\
\hline Corticosteroids & $79(75.2 \%)$ & Efficacy reported by $63.3 \%$ \\
\hline Adrenaline & $20(19.0 \%)$ & Efficacy reported by $15.0 \%$ \\
\hline Icatibant & $3(2.9 \%)$ & Efficacy reported by $66.7 \%$ \\
\hline Tranexamic acid & $1(<1 \%)$ & Efficacy reported by $0 \%$ \\
\hline Beta-2 agonists & $1(<1 \%)$ & Unknown effect \\
\hline Montelukast & $2(1.9 \%)$ & Unknown effect \\
\hline Azathioprine & $1(<1 \%)$ & Unknown effect \\
\hline \multicolumn{3}{|l|}{ Airway management } \\
\hline Intubation & 4 patients & $3.8 \%$ \\
\hline Tracheostomy & 1 patient & $0.9 \%$ \\
\hline
\end{tabular}

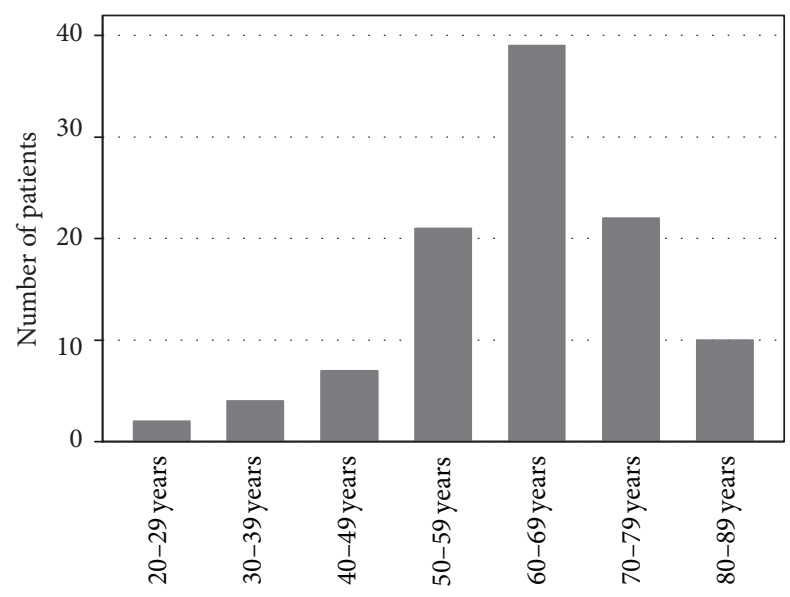

FIGURE 1: Age distribution of the cohort.

As a group, patients with ACEi induced angioedema had many concomitant diseases, predominantly associated with smoking, alcohol use, obesity, and allergic diseases. Using difference of proportion tests, the incidence of hypertension was not surprisingly overrepresented $(p<0.0001$; 95\% CI $0.66-1.04)$. Diabetes was shown to be a significant protective factor $(p<0.005$; 95\% CI $0.37-0.75)$ (Table 4$)$. The risk of angioedema was not found to correlate with smoking (Table 1)

In a minor fraction of patients, C-reactive protein or tryptase was elevated (Table 5). None of the patients with recurrent angioedema after ACEi withdrawal had a positive histamine-release (HR) test or elevated tryptase, but three had concomitant rash. All tested patients had normal complement $\mathrm{C} 1$ inhibitor levels and function.
Obvious parameters associated with admission to a hospital were intubation and tracheostomy. In multivariate logistic regression analysis, angioedema located in the head and neck region was nonsignificantly associated with admission (odds ratio (OR) 5.9 ( $p=0.15,95 \%$ CI 0.53-98.49)), while angioedema in peripheral sites was significantly associated with not being admitted (OR 0.15 ( $p=0.0595 \%$ CI, 0.010.95) (Table 6)).

\section{Discussion}

Our study confirmed female gender as a risk factor of ACEi induced angioedema ( $p=0.006$ ), which previously has been disputed [10]. A possible bias in our study could be more women than men being treated with an ACEi. To assess this, we used MedStat.dk, which is a tool to extract data on prescribed pharmaceuticals in Denmark [9]. In fact, the prescription rate of ACEi for men was 23\% higher than that for women, even though there are more women than men in this age group (typically $>45$ years of age). This further consolidates female gender as a risk factor. In hereditary angioedema, symptoms are often worse in women, presumably due to an interaction with estrogen, but this has never been studied in ACEi induced angioedema [11].

Smoking has been identified as a risk factor in earlier studies, but no association was found in this study [12, 13]. Diabetes seems to be a protective factor, which was confirmed by our study $(21 \%$ with versus $79 \%$ without diabetes, $p<$ 0.005) [14]. The negative correlation between diabetes and ACEi angioedema has not been fully understood. However, it seems that poor blood glucose control and high levels of HbAlc might increase the level of Dipeptidyl-Peptidase IV [15]. This enzyme is one of the main metabolizers of the vasoactive molecules bradykinin and substance $P$, which are 
TABLE 3: Data regarding hospital admissions and Emergency Department visits. Data was unknown regarding admissions in two patients. Three patients were admitted, but the number of admissions was unknown. Thus, they count as one admission each, even though some might have been admitted more than once; therefore, the number of hospitalizations is an approximated minimum. In five patients, the duration of admission was unknown. Diagnostic codes are from the International Classification of Diseases, Tenth Edition (ICD-10).

\begin{tabular}{|c|c|}
\hline Hospitalization data & \\
\hline Patients assessed at Emergency Department & 48 \\
\hline Patients admitted to a hospital & 55 \\
\hline Number of admissions, total & 74 \\
\hline 1 & 39 patients \\
\hline 2 & 7 patients \\
\hline 3 & 2 patients \\
\hline 4 & 4 patients \\
\hline Unknown number & 3 patients \\
\hline Days of admission, total & 143 \\
\hline Days of admission, mean, [range] & $2.9[1-35]$ \\
\hline \multicolumn{2}{|l|}{ Department of initial admission } \\
\hline (i) Internal Medicine & 40 \\
\hline (ii) Otorhinolaryngology & 19 \\
\hline (iii) Emergency Department & 6 \\
\hline (iv) Intensive Care Unit & 2 \\
\hline (v) Dermatology and Allergy & 2 \\
\hline (vi) Unknown & 5 \\
\hline \multicolumn{2}{|l|}{ Diagnostics codes in Emergency Department } \\
\hline (i) DT78.3 Quincke’s edema & $56.3 \%$ \\
\hline (ii) DT78.4 Allergy unspecified & $33.3 \%$ \\
\hline (iii) DT88.6 Anaphylactic shock & $2.0 \%$ \\
\hline (iv) Miscellaneous & $8.4 \%$ \\
\hline \multicolumn{2}{|l|}{ Diagnostic codes in other departments } \\
\hline DT78.3 Quincke’s edema & $59.6 \%$ \\
\hline DT78.4 Allergy unspecified & $15.9 \%$ \\
\hline DT88.6 Anaphylactic shock & $2.1 \%$ \\
\hline Miscellaneous & $18.1 \%$ \\
\hline Unknown & $4.3 \%$ \\
\hline
\end{tabular}

suspected to be the primary mediators for ACEi angioedema. In addition, low levels of Dipeptidyl-Peptidase IV have previously been correlated with ACEi angioedema [8].

Allergic rhinitis, asthma, and atopic dermatitis were not significantly associated with ACEi angioedema in this study. However, a few patients had positive HR test (2.9\%) and/or elevated tryptase (5.7\%). Those patients might have an underlying mast cell driven condition, which raised their a priori risk of angioedema during ACEi treatment. It has been proposed that an initial histamine-release reaction can set off bradykinin-mediated angioedema attacks, although this needs clarification $[16,17]$.

$6.7 \%$ had a positive family history of angioedema, but none of them had complement $\mathrm{Cl}$ inhibitor deficiency. Angioedema is relatively prevalent in the general population, and some families might have a genetic predisposition that
TABLE 4: Concomitant disease. Numbers do not add up to $100 \%$, as some patients had more than one concomitant disease.

\begin{tabular}{lc}
\hline Disease & Frequency, $n,(\%)$ \\
\hline Hypertension & $97(92.4 \%)$ \\
Diabetes & $23(21.9 \%)$, \\
Other ischemic heart disease & $16(15.2 \%)$ \\
Rheumatic disease & $14(13.3 \%)$ \\
Heart failure & $13(12.4 \%)$ \\
Hypercholesterolemia & $13(12.4 \%)$ \\
Allergic rhinitis & $10(9.5 \%)$ \\
Asthma & $9(8.6 \%)$ \\
COPD & $6(5.7 \%)$ \\
Atopic dermatitis & $6(5.7 \%)$ \\
Psychiatric disease & $5(4.8 \%)$ \\
Osteoporosis & $4(3.8 \%)$ \\
History of stroke & $4(3.8 \%)$ \\
Thyroid disease & $3(2.9 \%)$ \\
Cancer & $3(2.9 \%)$ \\
\hline
\end{tabular}

is not yet understood $[18,19]$. As expected, all tested patients had normal levels of complement $\mathrm{Cl}$ inhibitor.

Every fifth patient in our cohort had a description of rash/urticaria in their medical records. However, we suspect that both patients and physicians have trouble distinguishing between urticaria and angioedema, as some describe angioedema as "giant hives." Usually, ACEi angioedema is not associated with urticaria.

It has been proposed that a known idiopathic angioedema could increase the risk of attacks, when treated with ACEi, but as no data were available on idiopathic angioedema prior to ACEi treatment, we were not able to study this further [20]. African descent is another known risk factor both for angioedema due to ACEi and for the need for airway management, signifying a severe angioedema $[1,21]$. Our cohort did not include any patients of African descent, so we were not able to verify this previous finding.

The number of patients in need of acute airway management was a little higher than in a previous American study by Tai et al.: intubation $3.8 \%$ versus $3.3 \%$ and tracheostomy $0.9 \%$ versus $0.3 \%$ [1]. However, an earlier study from 2007 by Grant et al. displays a larger proportion of intubations, namely, 10\% [22]. The demographics in the United States of America and Denmark differ with regard to race, as more people in the US have African ancestry; this might have significance when comparing studies [22]. In the literature, an algorithm has been proposed for assessment and treatment of angioedema in the acute phase [23]. This is an important notion, since the hypopharynx and larynx are not visualized by a routine inspection of the oral cavity. In patients not assessed by an otorhinolaryngologist, close attention should be paid to clinical clues to a potential hypopharynx or larynx swelling: inability to swallow foods/liquids, changed voice, hoarseness, drooling, patient stating to feel a "lump in the throat," and stridor. Angioedema due to an ACEi tends to have a more severe clinical presentation than most other 
TABLE 5: Laboratory tests performed.

\begin{tabular}{|c|c|c|}
\hline Laboratory tests & Result & $\%$ of cohort \\
\hline \multirow{2}{*}{ Complement C1-inhibitor tests } & Normal & $72.4 \%$ \\
\hline & Not tested & $27.6 \%$ \\
\hline \multirow{4}{*}{ HR test chronic urticaria } & Negative & $55.2 \%$ \\
\hline & Not tested & $40.0 \%$ \\
\hline & Positive & $2.9 \%$ \\
\hline & Data missing & $1.9 \%$ \\
\hline Increased C-reactive protein & Range 7-126 (normal < 6 mg/L) & $14.3 \%$ \\
\hline Leukocytosis & More than $8.8 \times 10^{9} / \mathrm{L}$ & $15.2 \%$ \\
\hline Tryptase & More than $12 \mathrm{ng} / \mathrm{mL}$ & $5.7 \%$ \\
\hline
\end{tabular}

TABle 6: Multivariate logistic regression analysis. Association between different factors and the need for admission. ${ }^{*}$ Significant result, peripheral angioedema less likely to cause the patient to be admitted. ${ }^{1}$ High odds ratios for admission.

\begin{tabular}{|c|c|c|c|c|c|}
\hline & Odds ratio & Standard error & $z$ & $p>z$ & 95\% confidence interval \\
\hline Male versus female sex & 0.74 & 0.40 & -0.55 & 0.58 & $0.25-2.15$ \\
\hline Urticaria & 0.42 & 0.28 & -1.33 & 0.19 & $0.11-1.52$ \\
\hline Head and neck angioedema & $6.93^{1}$ & 9.05 & 1.48 & 0.14 & $0.53-98.49$ \\
\hline Peripheral angioedema & 0.14 & 0.14 & -2.00 & $0.05^{*}$ & $0.01-0.95$ \\
\hline Smoking & $2.02^{1}$ & 1.29 & 1.10 & 0.27 & $0.57-7.06$ \\
\hline Rash & 1.05 & 0.58 & 0.10 & 0.92 & $0.35-3.11$ \\
\hline Diabetes & 1.78 & 1.14 & 0.91 & 0.37 & $0.50-6.23$ \\
\hline Hypertension & 0.72 & 0.68 & -0.35 & 0.73 & $0.11-4.53$ \\
\hline Ischemic heart disease & 1.16 & 0.45 & 0.39 & 0.70 & $0.54-2.48$ \\
\hline Heart failure & 1.23 & 0.57 & 0.44 & 0.66 & $0.49-3.06$ \\
\hline Atopic dermatitis & 0.66 & 0.68 & -0.40 & 0.69 & $0.08-5.01$ \\
\hline Allergic rhinitis & $2.30^{1}$ & 2.15 & 0.89 & 0.37 & $0.37-14.39$ \\
\hline Asthma & 0.78 & 0.45 & -0.43 & 0.67 & $0.25-2.42$ \\
\hline
\end{tabular}

forms of angioedema, and deaths due to airway obstruction have been described [24].

The recurrence of angioedema in patients on continued ACEi treatment is 187 per 1000 patient-years, but with a rather long latency-on average 11 months to the next attack [25]. All patients in the present study had their ACEi discontinued after assessment at our department. During the follow-up period of 700 patient-months, 10 of 105 (9.5\%) patients experienced recurrent angioedema after the withdrawal of ACEi. A national registry based study found a similar recurrence rate of nine percent, while two retrospective clinical studies found higher recurrence rates [25-27]. A limitation of our study is that patients with mild or infrequent angioedema episodes might not have been rereferred to our department and thus not registered with recurrence. Mahmoudpour et al. found that $32-53 \%$ of patients with a first-time angioedema attack discontinued ACEi in 2007-2013 (increasing over the time period) [26]. Medical guidelines advise that ACEi should be replaced with an angiotensin 2-receptor blocker (ARB) if adverse drugs reactions occur [28]. In a recent study of ACEi adverse reactions, $43 \%$ of angioedema patients were switched to an ARB, 14\% switched to "other hypertensive drugs," and 14\% stopped without replacement therapy; the remainder stayed on ACEi [29]. Angioedema recurrence rates were not statistically different between patients that switched to various alternative hypertensive drugs (ARB 34\%, calcium antagonists 28\% and "other" 29\%, $t$-test and MannWhitney $U$ test $p>0.05$ ) [30]. One hypothesis is that ACEi treatment can be the trigger of a latent predisposition to (idiopathic) angioedema. However, genetic factors are also involved in ACEi angioedema, and in one patient multiple enzyme deficiencies were seen $[5,31]$.

The efficacy of antihistamines (62.5\%) and/or corticosteroids (63.3\%) reported by patients and physicians are most likely explained by a high spontaneous remission rate of ACEi angioedema, as the bradykinin pathway is not affected by classical antiallergic medication. It is noteworthy that we find the reported efficacy of antiallergic treatments is the same as for the newer drug icatibant, which is a selective bradykinin-2 antagonist. The low number of treated patients does not allow for any conclusions, but a previous study would suggest icatibant to be more effective than antiallergic treatment [32]. One of the important focus areas of medical science-personalized medicine-is aiming to find genetic and clinical factors that predict patients at risk of ACEi induced angioedema, and to these patients another drug should be prescribed. Until such tests and prediction models are available, physicians and patients rely on a thorough assessment of patients with angioedema in order to distinguish between ACEi induced and other types of angioedema. 


\section{Conclusion}

In conclusion, this study validates older age and female sex as risk factors of $\mathrm{ACEi}$ angioedema, while smoking habits and allergies were not associated. An important finding was that patients with diabetes seem to be protected against ACEi angioedema occurrence; this fact should be explored in upcoming studies. Patients with angioedema of the head and neck were admitted to hospital to a high extent due to the risk of airway obstruction, whereas patients with peripheral angioedema were less likely to be admitted.

\section{Additional Points}

Institutions where the work was performed are as follows: collection of data: Department of Dermatology and Allergy Centre, Odense University Hospital, Sdr. Boulevard 29, Entrance 142, 5000 Odense C, Denmark, with associated physicians: Georg Authried, Sumangali Chandra Prasad, Kristine Appel U. Pallesen, Kawa Khaled Ajgeiy, Shailajah Kamaleswaran, and Anette Bygum; analysis and statistics: Department of Otorhinolaryngology, Head \& Neck Surgery and Audiology, Rigshospitalet, University of Copenhagen, with associated physicians: Dr. Eva Rye Rasmussen and Dr. Christian von Buchwald.

\section{Disclosure}

This study is a part of Dr. Rasmussen's Ph.D. Level of evidence is $2 \mathrm{~b}$ (individual cohort study). This work was performed as part of the PREDICTION-ADR consortium study on angioedema.

\section{Competing Interests}

Dr. Eva Rye Rasmussen has previously collaborated with Shire $^{\circledR}$, MSD Norway ${ }^{\circledR}$, CSL Behring ${ }^{\circledR}$, and Viropharma ${ }^{\circledR}$ regarding research and teaching within the field of hereditary and pharmacologically induced angioedema. Anette Bygum has received research grant support and/or speaker/consultancy fees from CSL Behring, Viropharma, and Shire/Jerini AG and participated in a clinical trial for Jerini AG and BioCryst. She is an advisor for the HAE Scandinavian Patient Organization. She is a member of the IOS Steering Committee and participates in a clinical study in collaboration with BioCryst. Viropharma is now part of the Shire group of companies. Shire ${ }^{\circledR}$ has previously supported Dr. Eva Rye Rasmussen with a research grant for her studies on other skin manifestations in angioedema patients.

\section{Acknowledgments}

This study was not specifically supported, but the authors thank Shire ${ }^{\circledR}$ and CSL Behring ${ }^{\circledR}$ for their continued contribution to angioedema research. CSL Behring ${ }^{\circledR}$ has provided an unrestricted research grant for Dr. Eva Rye Rasmussen in support of her Ph.D. thesis on ACEi induced angioedema (20.000 Euro).

\section{References}

[1] S. Tai, M. Mascaro, and N. A. Goldstein, "Angioedema: a review of 367 episodes presenting to three tertiary care hospitals," Annals of Otology, Rhinology and Laryngology, vol. 119, no. 12, pp. 836-841, 2010.

[2] D. S. Roberts, E. J. Mahoney, C. T. Hutchinson, A. Aliphas, and K. M. Grundfast, "Analysis of recurrent angiotensin converting enzyme inhibitor-induced angioedema," The Laryngoscope, vol. 118, no. 12, pp. 2115-2120, 2008.

[3] J. P. Y. Holm and T. Ovesen, "Increasing rate of angiotensinconverting enzyme inhibitor-related upper airway angiooedema," Danish Medical Journal, vol. 59, no. 6, Article ID A4449, 2012.

[4] E. Ishoo, U. K. Shah, G. A. Grillone, J. R. Stram, and N. S. Fuleihan, "Predicting airway risk in angioedema: staging system based on presentation," Otolaryngology_Head and Neck Surgery, vol. 121, no. 3, pp. 263-268, 1999.

[5] G. Pare, M. Kubo, J. B. Byrd et al., "Genetic variants associated with angiotensin-converting enzyme inhibitor-associated angioedema," Pharmacogenetics and Genomics, vol. 23, no. 9, pp. 470-478, 2013.

[6] J. V. Gainer, C. M. Stein, T. Neal, D. E. Vaughan, and N. J. Brown, "Interactive effect of ethnicity and ACE insertion/deletion polymorphism on vascular reactivity," Hypertension, vol. 37, no. 1, pp. 46-51, 2001.

[7] A. V. Woodard-Grice, A. C. Lucisano, J. B. Byrd, E. R. Stone, W. H. Simmons, and N. J. Brown, "Sex-dependent and racedependent association of XPNPEP2 C-2399A polymorphism with angiotensin-converting enzyme inhibitor-associated angioedema," Pharmacogenetics and Genomics, vol. 20, no. 9, pp. 532-536, 2010.

[8] J. B. Byrd, K. Touzin, S. Sile et al., "Dipeptidyl peptidase IV in angiotensin-converting enzyme inhibitor-associated angioedema," Hypertension, vol. 51, no. 1, pp. 141-147, 2008.

[9] Statistics on the total sales of medicines in Denmark 1996-2015, 2016, http://www.medstat.dk/en.

[10] N. J. Brown, W. A. Ray, M. Snowden, and M. R. Griffin, "Black Americans have an increased rate of angiotensin converting enzyme inhibitor-associated angioedema," Clinical Pharmacology and Therapeutics, vol. 60, no. 1, pp. 8-13, 1996.

[11] L. Bouillet and A. Gompel, "Hereditary angioedema in women: specific challenges," Immunology and Allergy Clinics of North America, vol. 33, no. 4, pp. 505-511, 2013.

[12] J. B. Kostis, M. Packer, H. R. Black, R. Schmieder, D. Henry, and E. Levy, "Omapatrilat and enalapril in patients with hypertension: the omapatrilat cardiovascular treatment vs. enalapril (OCTAVE) trial," American Journal of Hypertension, vol. 17, no. 2, pp. 103-111, 2004.

[13] T. Morimoto, T. K. Gandhi, J. M. Fiskio et al., "An evaluation of risk factors for adverse drug events associated with angiotensinconverting enzyme inhibitors," Journal of Evaluation in Clinical Practice, vol. 10, no. 4, pp. 499-509, 2004.

[14] D. R. Miller, S. A. Oliveria, D. R. Berlowitz, B. G. Fincke, P. Stang, and D. E. Lillienfeld, "Angioedema incidence in US veterans initiating angiotensin-converting enzyme inhibitors," Hypertension, vol. 51, no. 6, pp. 1624-1630, 2008.

[15] E. Mannucci, L. Pala, S. Ciani et al., "Hyperglycaemia increases dipeptidyl peptidase IV activity in diabetes mellitus," Diabetologia, vol. 48, no. 6, pp. 1168-1172, 2005. 
[16] T. Renné, “The procoagulant and proinflammatory plasma contact system," Seminars in Immunopathology, vol. 34, no. 1, pp. 31-41, 2012.

[17] T. Renné, A. H. Schmaier, K. F. Nickel, M. Blombäck, and C. Maas, "In vivo roles of factor XII," Blood, vol. 120, no. 22, pp. 4296-4303, 2012.

[18] F. Madsen, J. Attermann, and A. Linneberg, "Epidemiology of non-hereditary angioedema," Acta Dermato-Venereologica, vol. 92, no. 5, pp. 475-479, 2012.

[19] B. L. Zuraw, K. Bork, K. E. Binkley et al., "Hereditary angioedema with normal $\mathrm{C} 1$ inhibitor function: consensus of an international expert panel," Allergy and Asthma Proceedings, vol. 33, pp. 145-156, 2012.

[20] N. Orfan, R. Patterson, and M. S. Dykewicz, "Severe angioedema related to ACE inhibitors in patients with a history of idiopathic angioedema," The Journal of the American Medical Association, vol. 264, no. 10, pp. 1287-1289, 1990.

[21] E. J. Mahoney and A. K. Devaiah, "Angioedema and angiotensin-converting enzyme inhibitors: are demographics a risk?" Otolaryngology - Head and Neck Surgery, vol. 139, no. 1, pp. 105-108, 2008.

[22] N. N. Grant, Z. E. Deeb, and S. H. Chia, "Clinical experience with angiotensin-converting enzyme inhibitor-induced angioedema," Otolaryngology — Head and Neck Surgery, vol. 137, no. 6, pp. 931-935, 2007.

[23] J. J. Moellman, J. A. Bernstein, C. Lindsell et al., "A consensus parameter for the evaluation and management of angioedema in the emergency department," Academic Emergency Medicine, vol. 21, no. 4, pp. 469-484, 2014.

[24] S. J. Kim, J. C. Brooks, J. Sheikh, M. S. Kaplan, and B. J. Goldberg, "Angioedema deaths in the United States, 1979-2010," Annals of Allergy, Asthma and Immunology, vol. 113, no. 6, pp. 630-634, 2014.

[25] N. J. Brown, M. Snowden, and M. R. Griffin, "Recurrent angiotensin-converting enzyme inhibitor-associated angioedema," The Journal of the American Medical Association, vol. 278, no. 3, pp. 232-233, 1997.

[26] S. H. Mahmoudpour, F. W. Asselbergs, I. Terreehorst, P. C. Souverein, A. De Boer, and A. H. Maitland-Van Der Zee, "Continuation of angiotensin converting enzyme inhibitor therapy, in spite of occurrence of angioedema," International Journal of Cardiology, vol. 201, pp. 644-645, 2015.

[27] L. Beltrami, A. Zanichelli, L. Zingale, R. Vacchini, S. Carugo, and M. Cicardi, "Long-term follow-up of 111 patients with angiotensin-converting enzyme inhibitor-related angioedema," Journal of Hypertension, vol. 29, no. 11, pp. 2273-2277, 2011.

[28] P. V. Dicpinigaitis, "Angiotensin-converting enzyme inhibitorinduced cough: ACCP evidence-based clinical practice guidelines," Chest, vol. 129, no. 1, pp. 169S-173S, 2006.

[29] S. H. Mahmoudpour, F. W. Asselbergs, C. E. de Keyser et al., "Change in prescription pattern as a potential marker for adverse drug reactions of angiotensin converting enzyme inhibitors," International Journal of Clinical Pharmacy, vol. 37, no. 6, pp. 1095-1103, 2015.

[30] M. Cicardi, L. C. Zingale, L. Bergamaschini, and A. Agostoni, "Angioedema associated with angiotensin-converting enzyme inhibitor use: outcome after switching to a different treatment," Archives of Internal Medicine, vol. 164, no. 8, pp. 910-913, 2004.

[31] E. Beaudouin, F. Defendi, J. Picaud, C. Drouet, D. Ponard, and D. A. Moneret-Vautrin, "Iatrogenic angioedema associated with ACEi, sitagliptin, and deficiency of 3 enzymes catabolizing bradykinin," European Annals of Allergy and Clinical Immunology, vol. 46, no. 3, pp. 119-122, 2014.

[32] M. Baş, J. Greve, K. Stelter et al., "A randomized trial of icatibant in ace-inhibitor-induced angioedema," New England Journal of Medicine, vol. 372, no. 5, pp. 418-425, 2015. 


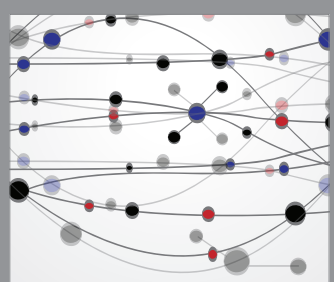

The Scientific World Journal
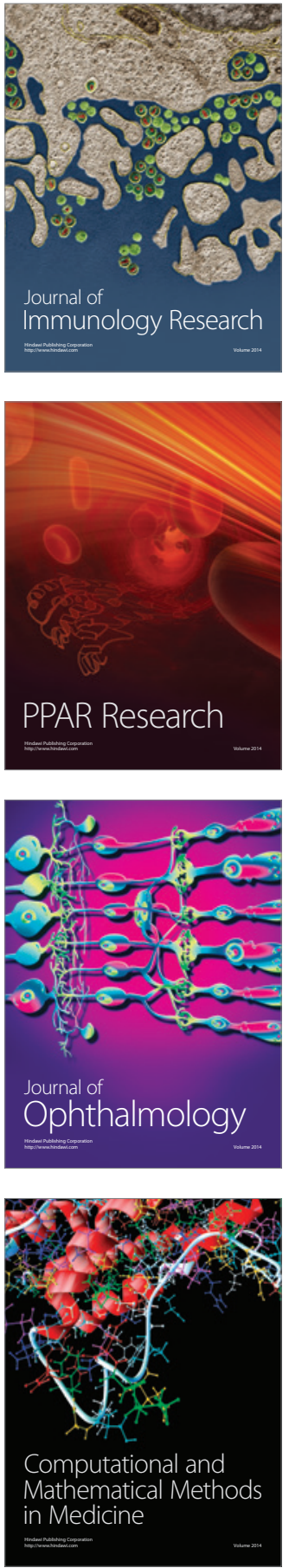

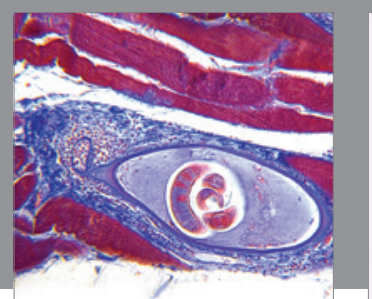

Gastroenterology Research and Practice
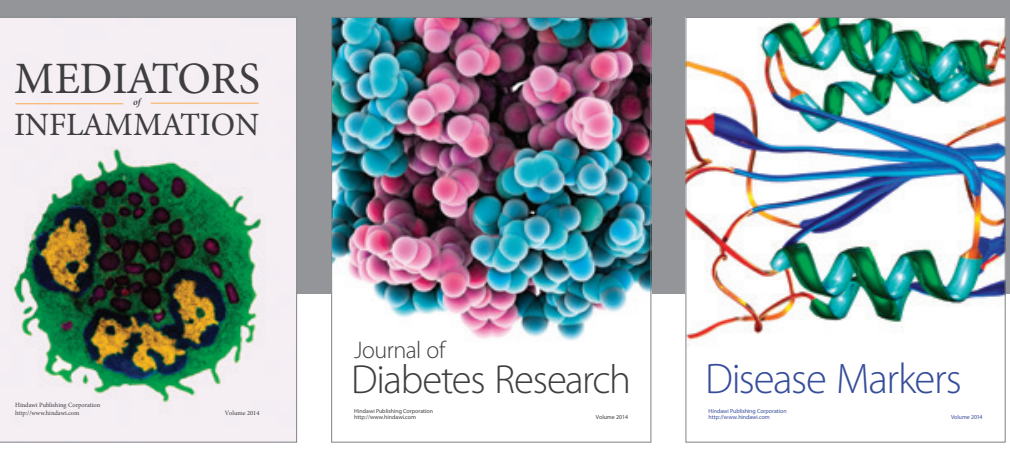

Disease Markers

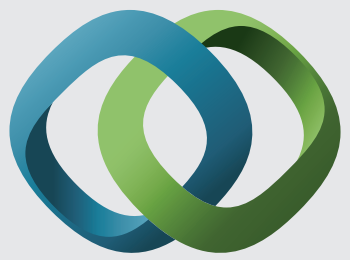

\section{Hindawi}

Submit your manuscripts at

https://www.hindawi.com
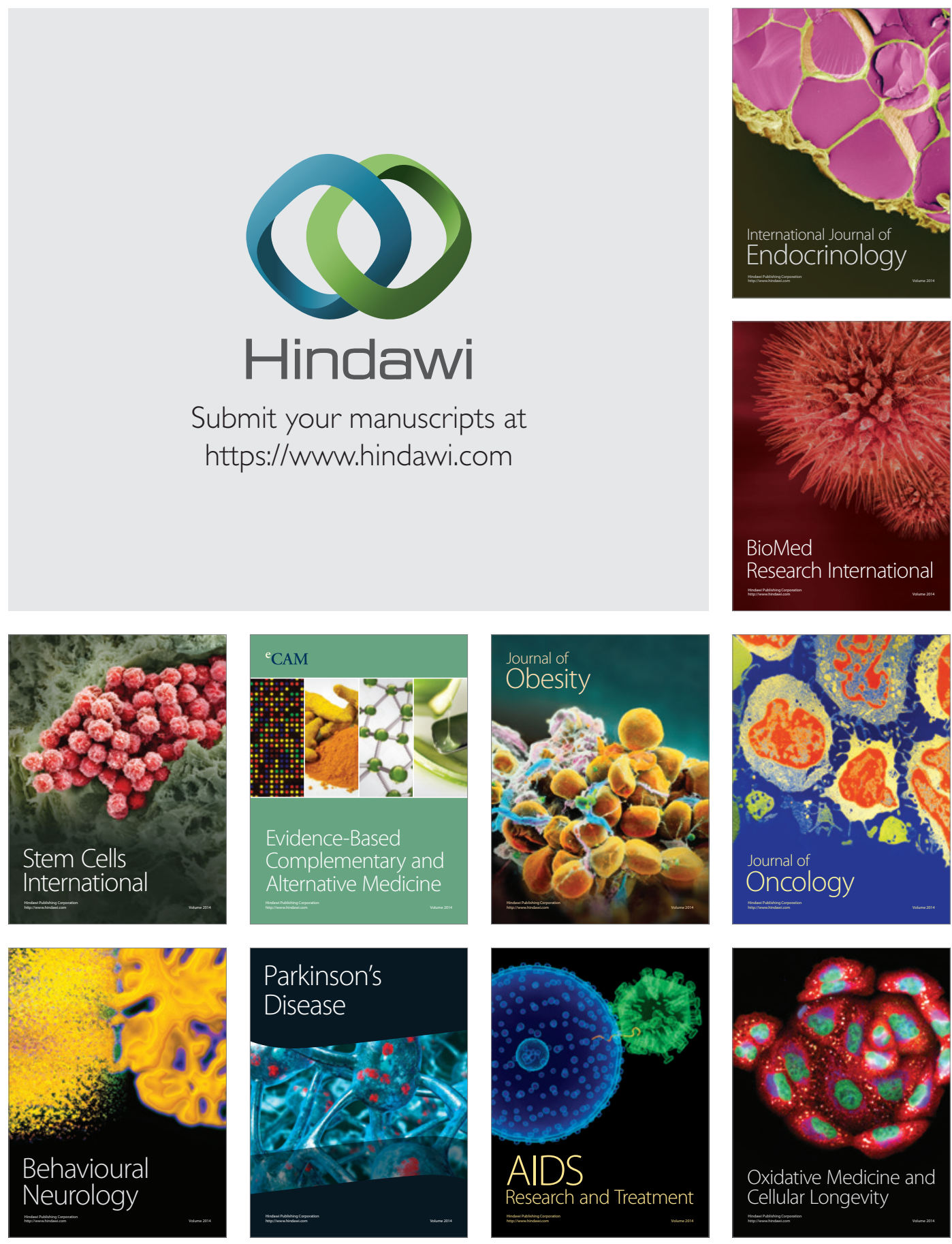